\title{
A Proposta de Acolhimento: sua formulação e implantação nas unidades de atenção primária do Sistema Único de Saúde no Município de Belo Horizonte
}

Heloisa Helena Silva Moreira

\section{Introdução}

A Proposta de Acolhimento teve por objetivo garantir o acesso às unidades de atenção primária do Sistema Único de Saúde (SUS) em Belo Horizonte. O problema, que se pretendia solucionar, manifestava-se em enormes filas às portas dessas unidades, durante as madrugadas e bem cedo de manhã. A situação era, indubitavelmente, injusta e desumana, e muitas vezes ocupou o noticiário local por serem frequentes as queixas dos usuários e dos trabalhadores sobre o atendimento deficiente.

A Proposta de Acolhimento surgiu em Belo Horizonte em um contexto de grandes mudanças iniciadas pelo governo da Frente-BH-Popular ${ }^{1}$, liderada pelo Partido dos Trabalhadores (PT), que alimentou muitas expectativas ao anunciar novos rumos para o período em que foi eleita - 1993 a 1996. No intuito de atendê-las, vários projetos e programas foram desenvolvidos nos diversos órgãos e secretarias municipais, tendo em vista a prioridade para aquela gestão: a criança. 
Na Saúde, área das mais destacadas no plano de governo, uma das questões que reclamava nova orientação era o alto índice de mortalidade infantil do município.

Visando solucionar o problema, a Gerência de Epidemiologia da Secretaria Municipal de Saúde da Prefeitura Municipal de Belo Horizonte (SMSA/PBH) desenvolveu, no primeiro ano, um Projeto de Vigilância à Mortalidade Infantil com enfoque no risco. Colocado em prática, o projeto passou a classificar os nascidos vivos menores de um ano de idade de acordo com três critérios: filhos de mães analfabetas, com baixo peso e residentes em áreas de risco.

Embora a estratégia tivesse comprovado sua efetividade na localização e priorização dessas crianças, em um primeiro agendamento para as unidades de atenção primária, ela tornou evidente que o nível de assistência não lhes garantia a continuidade de acesso. Era preciso reformular o processo de trabalho das unidades de atenção primária e isso implicava a participação de outra gerência no projeto: a Coordenação de Atividades Assistenciais, que atualmente corresponde à Gerência de Assistência (Geas). Ela era a responsável pela organização do trabalho nas unidades e passou a integrar o grupo de discussão do nível central da SMSA/PBH.

As duas gerências - Epidemiologia e Assistência - passaram a procurar resposta para a seguinte questão: por que o Projeto de Vigilância à Mortalidade Infantil não atingia seu objetivo embora fosse considerado, por ambas, adequado do ponto de vista técnico?

A resposta que estava se tornando unânime no grupo era a de que o projeto não tocava no problema central: o acesso. Além disso, a forma de organização do trabalho nas unidades de atenção primária resultou, segundo o mesmo grupo, na subutilização dos recursos humanos e na desumanização do acesso. Chegaram à conclusão que o acesso estava sendo barrado por uma regra a qual estipulava número predeterminado de consultas, atendidas por ordem de chegada, em respeito a um acordo burocrático firmado com o Sindicato dos Médicos. Havia ainda outro fator: a compreensão, por parte dos trabalhadores das unidades, de que não lhes cabia atender urgências, ou seja, casos agudos que eram por eles identificados como urgências.

Tais problemas foram encaminhados à IV Conferência Municipal de Saúde, que votou, segundo Queiroz (1998), a proposta de elaboração e implementação de projeto que tivesse como prioridade o atendimento ao agudo em todos os centros de saúde ${ }^{2}$. A proposta foi eleita como a prioridade da saúde naquela conferência. Assim, em 1994 teve início o Projeto Vida, cujas ações se voltaram para a reorganização da assistência à gestante e à criança no município.

No I Seminário de Avaliação do Projeto Vida, constatou-se que as dificuldades de acesso aos centros de saúde e de priorização do agudo ainda persistiam ${ }^{3}$. Tanto que, no II Seminário de Avaliação desse projeto, a principal proposta referiase à formulação de outro modelo de organização dos serviços. Posteriormente chamada de "acolhimento", a nova proposta pretendia "abrir a porta" dos centros de saúde na expectativa de solucionar as dificuldades de acesso e acabar com as filas na entrada das unidades.

A despeito do empenho da SMSA/ $\mathrm{PBH}$ para institucionalizar o acolhimento concretizado em apresentações do tema em seminários para toda a rede, nas discussões em reuniões regulares com os gestores e 
em farta documentação sobre sua conceituação e importância -, sua metamorfose distanciou a proposta da definição e dos princípios defendidos no desenho original. Saber por que o acolhimento não se institucionalizou da forma como foi concebido é a finalidade deste trabalho.

A pesquisa realizada possibilitou conhecer, concretamente, como está sendo desenvolvido o acolhimento nas unidades de atenção primária do SUS em Belo Horizonte. Foram analisadas sua formulação e implantação, procurando obter informações que pudessem explicar o distanciamento da concepção original. A pesquisa de campo com entrevistas semiestruturadas foi utilizada primeiramente com três atores que participaram ativamente da construção da Proposta de Acolhimento: dois gestores e um consultor. Posteriormente, foi entrevistada uma equipe do Programa Saúde da Família (PSF) de cada uma das duas unidades de atenção primária, nas quais a prática do acolhimento foi apontada, pelo nível central da SMSA/PBH, como sendo a mais próxima e a mais distante da proposta. Para ouvir alguns usuários utilizou-se o método de saturação nas entrevistas semiestruturadas.

\section{A formulação da proposta}

A experiência prévia de um dos componentes do grupo de discussão do nível central da SMSA/PBH com o Projeto Porta Aberta, na cidade de Ipatinga (MG), e o estudo que esse grupo vinha desenvolvendo a respeito do Modelo de Defesa da Vida, de Campinas (São Paulo), passaram a fundamentar a formulação do acolhimento.

Segundo Carneiro (2004), há dois caminhos para a escolha da opção de ação.
O primeiro procura formar uma visão compreensiva da realidade, teoricamente fundamentada no raciocínio lógico, e estabelecer relações de causalidade e possíveis combinações entre meios e fins que sirvam para orientar o processo decisório. $\mathrm{O}$ segundo busca fazer um levantamento do estoque de conhecimento sobre formulação, implementação e avaliação de políticas públicas com vistas a adotar uma prática já experimentada ou em uso.

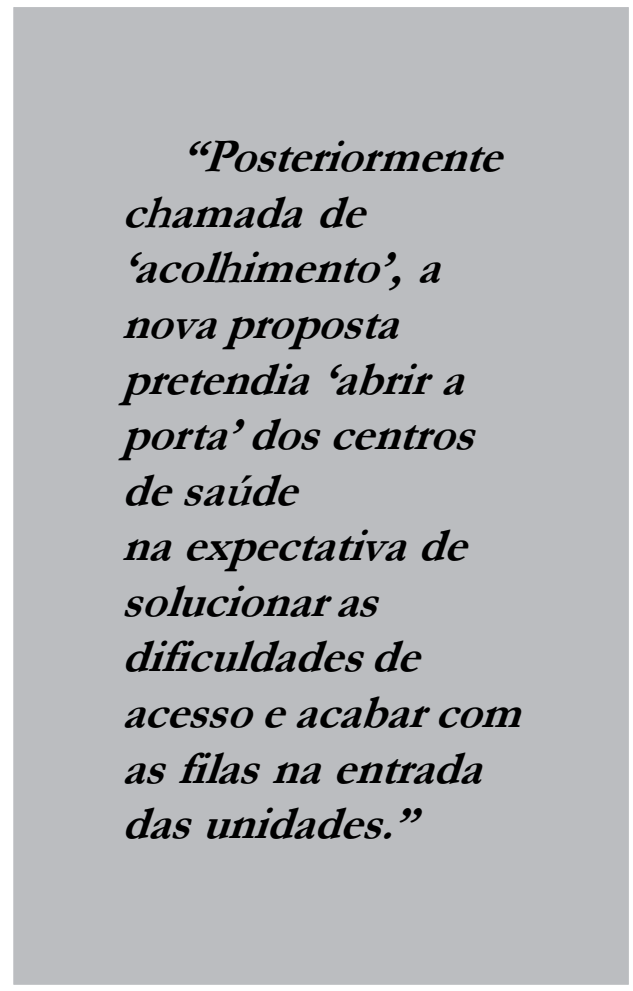

Quando não há condições de conhecer plenamente o que é possível fazer e as consequências e efeitos das várias alternativas de ação, prevalece uma forte tentação de seguir "a trilha do sucesso". É quando se faz opção por soluções que se transformam, ou são transformadas, em referências institucionalizadas para a ação por serem vistas como "boas práticas de gestão" capazes de atender, de forma 
adequada, ao que se quer alcançar. Mas alerta o autor: "a replicação de experiências exitosas não assegura, necessariamente, resultados igualmente exitosos", podendo tornar-se um caminho traiçoeiro porque poderá conduzir a resultados, não raras vezes, opostos aos esperados. (CARNEIRO, 2004)

A escolha da estratégia de acolhimento parece ter-se fundamentado, principalmente, em experiências prévias consideradas bem-sucedidas pelo grupo de discussão do nível central da SMSA/PBH. Esse tipo de referência, conclui Carneiro (2004), não se apresenta como uma boa credencial para substituir a previsão e a dedução teóricas como ferramentas na produção do conhecimento.

Essa pode ter sido uma das razões pelas quais a Proposta de Acolhimento tomou rumos indesejáveis e inesperados, tornando inaceitável o que vem sendo praticado, segundo as Recomendações para Organização da Atenção Básica na Rede Municipal (SMSA/PBH, 2003). De acordo com Queiroz (1998), outra razão para as dificuldades de concretização da Proposta de Acolhimento parece estar relacionada às falhas na própria concepção da estratégia, que não define claramente seus princípios e objetivos, e à ausência de indicadores claros e precisos dos resultados e do impacto.

Inicialmente associada ao Projeto Vida, da clínica pediátrica que tinha como objetivo a priorização do agudo com vistas a reduzir a mortalidade infantil, a estratégia de acolhimento foi, após várias deliberações das conferências municipais, difundindo-se para outras clínicas e ampliando seus objetivos para universalização do acesso e humanização do atendimento. A compreensão do que trata realmente o acolhimento - se priorização de crianças em processo agudo, se recepção do usuário ou uma postura acolhedora em todas as atividades - parece ter dificultado, sobremaneira, sua prática.

Para Queiroz, no entanto, um dos principais motivos das controvérsias em relação à Proposta de Acolhimento reside no fato de que os problemas aos quais se propõe resolver são amplos, a ponto de a estratégia se tornar insuficiente para abordá-los, inviabilizando sua solução.

Pode-se perceber também, pelas declarações dos idealizadores do acolhimento, que a formulação da proposta desenvolveu-se de acordo com o modelo vertical de formulação de políticas, ou seja, top-down, de cima para baixo, do grupo gestor do nível central da SMSA/PBH para os outros níveis: "Começamos a pautar essa discussão e dentro disso foi gestada a concepção do acolhimento. [...] dentro de um grupo gestor, o do Projeto de Vigilância à Mortalidade Infantil ${ }^{4}$."

Sabe-se que a construção de uma política envolve diferentes visões e interesses, responsáveis por uma boa dose de conflitos. Por isso, a definição do problema, a geração e a seleção da alternativa de ação, fatores fundamentais para conferir sustentabilidade e legitimidade à política, devem-se desenvolver de forma transparente e consensual. No modelo vertical, no entanto, a política decide e a administração implementa (MolinA, 2002).

O grupo de discussão do nível central da SMSA/PBH já havia definido que o problema era "acesso", cujo sinônimo parecia ser "porta e agenda abertas". Baseados em experiências anteriores, definiram a estratégia de acolhimento para solucioná-lo:

Então, a gente tinha alguns exemplos, de alguns locais, de algumas pessoas que participaram da construção da 
experiência, especialmente em Ipatinga, e uma retaguarda teórica que discutia um pouco isso e embasava o papel da atenção básica ${ }^{5}$.

Mas, quanto menos participativo o processo de construção de uma política, mais os envolvidos em sua aplicação se sentem desvinculados da proposta e descomprometidos com os resultados. $\mathrm{Na}$ verticalidade do modelo, está implícito que à medida que se desce na aplicação da política - ou seja, do nível central para a base -, as atividades vão perdendo força e interesse (Molina, 2002).

A verticalidade do modelo de construção da Proposta de Acolhimento contribuiu de forma decisiva para o envolvimento parcial e o comprometimento insuficiente dos trabalhadores porque, principalmente os que deveriam implementá-la - os trabalhadores de base -, não participaram da definição do problema nem da construção da sua proposta de solução.

Embora tivesse ocorrido o contato posterior do nível central com a base, esse visava envolver o maior número de trabalhadores na aceitação do que havia sido previamente definido. O objetivo era comunicar e formatar a proposta às condições locais.

$\mathrm{Na}$ verdade, a equipe dirigente da secretaria identificava o problema e também sabia qual ia ser [...] se o problema é acesso você tem que mexer na estratégia de trabalho. Então, de alguma forma, a gente já tinha também como. E aí, nesse percurso era fundamental que a gente envolvesse também o maior número possível de atores, digamos, [...] no partilhamento da nomeação desse problema e no desenho das causas ${ }^{6}$.
Na Plenária Municipal de Saúde, em maio de 1998, segundo Queiroz (1998), ficou decidido, sob um clima bastante conflituoso, que a continuidade do acolhimento não seria colocada em votação por não existirem informações suficientes sobre seus resultados. O documento que continha as propostas dos trabalhadores era pessimista em relação à Proposta de Acolhimento. Ele reivindicava a solução de sua continuidade. Mas o documento não foi encaminhado para discussão na plenária sob a alegação de que não era representativo dos trabalhadores.

Em algumas entrevistas, os atuais trabalhadores de base revelam, de forma muito clara, como percebem a Proposta de Acolhimento nas unidades de atenção primária, nos dias de hoje:

É muito serviço burocrático. A gente não tem tempo para trabalhar a intersetorialidade que é o que poderia fazer alguma diferença no morro. Outro estrangulamento é a deficiência das especialidades. As deficiências da saúde eles jogam pra cima da gente e o paciente vem discutir e se queixar do serviço aqui. Às 7 horas da manhã a gente chega e aquela quantidade de gente $[. .$.$] tem que ser rápido e não dá$ pra ser de qualidade. O problema de atender muito rápido é que muitas vezes eu vejo outro problema, por exemplo, de alimentação, e não dá tempo de abordá-lo. Esse problema irá aparecer 10 anos depois. Então, medicina preventiva não dá prá fazer. A parte mais difícil que tem na unidade é o acolhimento. Em toda unidade o que mais atormenta é o acolhimento. Tinha que estipular um número de consultas por dia. Passam umas 40 pessoas por $\mathrm{dia}^{7}$ pelo acolhimento. $\mathrm{O}$ 
usuário fica insatisfeito, o médico fica insatisfeito porque não tem como atender bem, fica uma consulta muito corrida ${ }^{8}$.

Na visão dos usuários a situação não é muito diferente. Suas declarações, de certa forma, fazem uníssono com as declarações dos trabalhadores:

É muito rápido. Não dá pro médico saber o que a gente tem. Tinha que ter mais agentes para atender; tem vez que a gente fica muito tempo esperando. A doutora sempre está muito cheia. Tenho dó dela. Por que a consulta especializada demora tanto? Acho que devia melhorar a consulta especializada. Às vezes a gente precisa com urgência e demora seis meses ou um ano?.

Algumas das falas são também eco de muitas declarações dos trabalhadores e usuários em outras épocas, como sugerem diversas pesquisas.

Ao investigar o acesso e a resolubilidade da Proposta de Acolhimento, Guimarães (1997), em suas considerações finais, conclui que, mesmo depois de transcorridos dois anos de implantação da Proposta de Acolhimento no Centro de Saúde Noraldino de Lima,

[...] os resultados obtidos ainda não são adequados à Proposta de Acolhimento. [...] a própria instituição tem-se omitido em proporcionar recursos humanos e materiais para o desenvolvimento dessa atividade, contribuindo para agravar ainda mais a situação (GuimarãEs, 1997, p.39-40).

O Estudo de Demanda do Acolhimento do Centro de Saúde Pedreira Prado
Lopes (2004) entrevistou 224 usuários, dos quais $46,4 \%$ consideraram a demora no atendimento como o fator de maior aborrecimento; $18,3 \%$ sugeriram aumentar o número de profissionais na unidade; e $15,2 \%$, melhorar a agilidade no atendimento. Esses percentuais são significativos, mesmo se considerados isoladamente. No entanto, pode ser facilmente verificado que essas três categorias de respostas estão tratando da mesma questão: a demora no atendimento. Dessa forma, esses percentuais somados tornam-se ainda mais significativos.

Um fator importante para a consecução dos objetivos de uma política pública é o modelo causal. Um modelo causal equivocado implica um diagnóstico incorreto da situação e terá como consequência distorções na formulação da política. Frequentemente, os modelos causais não levam em conta o fenômeno em si, mas determinados fatores que atuam sobre ele e provocam sua redução ou aumento (Silva e Melo 2000).

No que se refere ao modelo causal da Proposta de Acolhimento, pode-se perceber, nas entrevistas dos idealizadores, que o problema "acesso" aparece vinculado ao número limitado de consultas. ${ }^{10}$ Fica estabelecida uma causa para a dificuldade de acesso aos serviços das unidades de atenção primária do SUS em Belo Horizonte: a limitação das consultas médicas.

Porém, tendo-se em conta que a demanda é sempre maior que a oferta, nas unidades de saúde pública em todos os países, e que a possibilidade de atender a todos é sempre muito limitada, as 12 consultas médicas diárias, por turno, negociadas com o Sindicato dos Médicos em Belo Horizonte, podem ter funcionado como tentativa de viabilizar o atendimento em uma organização de trabalho 
centrada na consulta médica. Assim, o número limitado de consultas médicas apenas aumentou a dificuldade de acesso aos serviços de atenção primária à saúde, mas o fenômeno em si (acesso) não foi solucionado com a abertura da agenda.

A abertura da agenda médica solucionou o problema das filas da madrugada, deu destaque ao critério de risco e desencadeou processo de melhor aproveitamento do potencial da maioria dos trabalhadores que eram subutilizados na assistência, resultando em um melhor fluxo de trabalho nas unidades. Essa medida foi o ponto de partida para outras mudanças que culminaram na melhoria da assistência. Porém, nessas unidades foram e ainda são oferecidas condições em que "receber o paciente o dia todo não é possível. Como a gente recebe um número muito grande de pacientes por dia, a gente não dá conta de atender todo mundo e isso está gerando tumulto" $"$.

De fato, o acesso é uma variável dependente de múltiplos fatores e é disso que advém sua complexidade. Tendo havido crescimento nos recursos investidos, tanto municipais quanto federais, foi possibilitada a ampliação dos serviços e a melhoria do acesso. A folha de pagamento, por exemplo, passou de $\mathrm{R} \$ 15,9$ milhões em 1993 para R\$121,6 milhões em 1997. $\mathrm{O}$ investimento em recursos humanos, por concurso e terceirização, significou aumento dos postos de trabalho de 6.432, em dezembro de 1992, para 9.685 em fevereiro de 1997 - um acréscimo de 50,2\% -, além do aumento na compra de medicamentos (MALTA, 2001).

Portanto, o acesso não implica apenas que a porta da unidade e a agenda fiquem abertas durante todo o dia. Essa abertura tem que resultar, efetivamente, na entrega de um serviço. A ênfase no número de consultas negociadas junto à categoria médica colocou como coadjuvantes os fatores que poderiam ser, de fato, os protagonistas da falta de acesso, obscurecendo, dessa forma, a compreensão e a análise do contexto responsável pelas intermináveis filas nas unidades de atenção primária12. Quanto ao "pacto" sobre o papel da atenção básica, a que se referiu um dos gestores entrevistados, seu fundamento parece residir no fato de que a con-

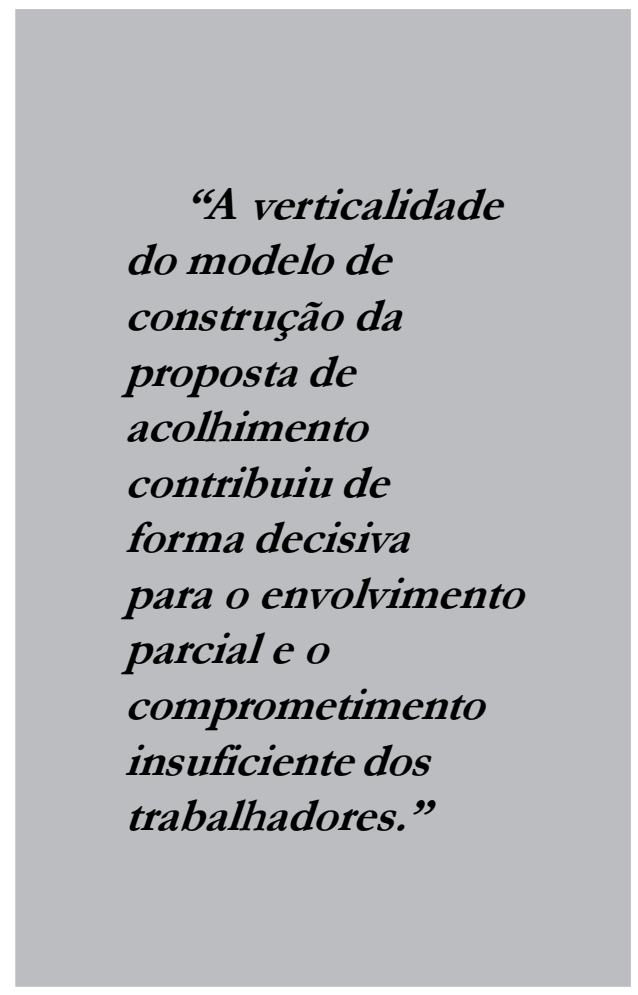

dição de saúde da população-alvo atendida no SUS pode, repentinamente, transformar resfriado em pneumonia, o que torna o atendimento do agudo um caso potencial de urgência.

Como os trabalhadores das unidades de atenção primária não possuem capacitação e habilitação para o atendimento de urgência e as unidades não dispõem do equipamento necessário para fazê-lo, um 
dos maiores receios dos trabalhadores é de que um paciente venha a óbito. Além do ônus emocional que isso pode representar para o trabalhador, paira sobre eles, o tempo todo, a ameaça de denúncias ou processos por negligência ou imperícia, mesmo na ausência de óbito.

\section{A implantação da proposta}

Quanto à implantação da Proposta de Acolhimento nas unidades de atenção primária do SUS em Belo Horizonte, parece ter-se desenvolvido também top-down, de cima para baixo, de acordo com o modelo vertical de implantação de políticas; ou seja, do grupo gestor do nível central da SMSA/PBH para os outros níveis. ${ }^{13}$ Parece ter-se fundamentado também na suposição ingênua e irrealista, segundo Silva e Melo (2000), de que a administração pública funciona por meio de "um mecanismo operativo perfeito", que pode assegurar a fidelidade de implantação da política ao seu desenho original "como um jogo de uma só rodada".

Muitas mudanças foram acontecendo, ao longo do processo de implantação do acolhimento, e seus resultados se mostraram diferentes dos esperados na proposta original. Todavia, resultados diferentes do esperado e desviados do desenho original não são, necessariamente, indesejáveis. Se as mudanças no desenho e nos resultados tivessem sido percebidas como uma sinalização para a necessidade de adaptações da proposta, isso poderia ter contribuido para enriquecê-la e adequála às mudanças do contexto.

Na visão estratégica da implantação de políticas, a ideia de rota como trajetória preconcebida é substituída pela compreensão de que decisões autônomas induzem a um processo de aprendizagem, que tanto pode contribuir para reformular como pode, no seu limite, levar à reversão ou substituição da política.

Os regimes democráticos que defendem alimentação, habitação, educação e saúde pública com discurso fortemente retórico podem ser submetidos a grandes pressões, no sentido de estender os benefícios sociais aos amplos setores da população aos quais se dirigem e que foram, tradicionalmente, ignorados por governos mais elitistas e autoritários; traduzindo-os, rapidamente, em recompensas políticas tangíveis que demonstrem compromisso com esses segmentos (GRINDLE, 1992).

O problema que se pretendia solucionar com a Proposta de Acolhimento era uma necessidade social da qual as autoridades públicas do Município de Belo Horizonte não podiam escapar. Não foi gratuitamente ou por acaso que esse "estado de coisas" se tornou de interesse público e passou a constar na agenda do governo local.

A repercussão política das filas na madrugada, desencadeada pela mídia, gerou forte pressão sobre a administração municipal e pode ter sido variável importante na decisão dos gestores de priorizar "abrir a porta" das unidades de atenção primária. É provável que a escolha de "abrir a porta" tenha envolvido cálculos relacionados à disponibilidade de recursos e à definição de prioridades. Outras medidas, como a solução da insuficiência de leitos hospitalares, de consultas especializadas e fornecimento regular de medicação, demandariam demoradas negociações com outros níveis de governo e custos mais altos.

A “porta aberta” estabeleceu o laço benfeitor/beneficiado, traduzindo-se em recompensa política tangível: a imediata entrada no serviço. Mas a entrada no 
serviço não significa necessariamente acesso. A obtenção do cuidado necessário à saúde, pelo uso dos serviços sempre que houver um problema ou a cada novo episódio de um mesmo problema, é o que, a rigor, define acessibilidade. É a obtenção do cuidado que concretiza o acesso.

O planejamento deve-se contrapor à intempestividade e improvisação na escolha das condutas ou procedimentos adequados. Seu papel é exatamente o de contribuir para a eficiência e eficácia das políticas priorizadas pelo governo. Mas, de acordo com Carneiro (2004), o planejamento só faz sentido quando existem várias alternativas de ação a serem consideradas no processo decisório. Quando o agente opera segundo restrições ou imposições advindas do ambiente ou de acordo com uma preferência inequívoca sobre o que fazer, o planejamento torna-se dispensável.

Não raras vezes, a linha de intervenção já se encontra previamente traçada e o que se faz é apenas reafirmá-la, construindo um argumento técnico para dar embasamento à escolha feita. São circunstâncias onde o planejamento atende apenas a propósitos de justificar e conferir "legitimidade" à decisão tomada, pouco se distinguindo de uma mera formalidade (CARNEIRO, 2004).

Assim parece ter acontecido com a Proposta de Acolhimento. A linha de intervenção já se encontrava previamente traçada ${ }^{14}$ e as consultas limitadas parecem ter constituído um argumento técnico legítimo que a reafirmou. Apesar do empenho da SMSA/PBH, a Proposta de Acolhimento não chegou a ser plenamente institucionalizada. Seu processo foi conflitivo, descontínuo e malsucedido, transformando seu desenho original, imprevisivelmente, em equipes escaladas para acolhimento com horários e locais definidos.

A ritualização da prática de acolhimento contraria as Recomendações para Organização da Atenção Básica na Rede Municipal (SMSA/PBH, 2003), que ainda considera inaceitável o fato de não haver acolhimento durante todo o horário de funcionamento da unidade. Mas essa parece ser a forma peculiar que os trabalhadores das unidades desenvolveram para participar na elaboração da Proposta de Acolhimento: foram incorporando seu estilo pessoal de atuação à política e transformando seu desenho original.

Pelas próprias características do trabalho de base, os trabalhadores precisam da autonomia discricionária para executá-lo. Por isso, de acordo com Lipsky (1996), eles não devem ser constrangidos por relações de subordinação ou regras e instruções burocráticas que possam representar limitações às suas alternativas, porque precisam determinar suas prioridades e desenvolver critérios pessoais sobre a aplicação dos serviços. Assim, eles podem considerar legítimo o direito de estabelecer suas próprias regras e ilegítimas as "recomendações" elaboradas por seus superiores.

À primeira vista, a ritualização do acolhimento poderia ser interpretada como contrária aos objetivos da SMSA/ $\mathrm{PBH}$. Mas, de fato, pode ser um mecanismo de balizamento que os trabalhadores utilizam para manter o fluxo de entrada no sistema público de saúde do município em níveis suportáveis, evitando o colapso, alongando a sobrevida, tornando possível a continuidade.

A mudança de governo, simultaneamente à municipalização da política nacional 
de saúde, e a posterior mudança do modelo assistencial representaram reformas de grandes proporções para o Município de Belo Horizonte e também podem ter trazido grandes desafios ao processo de implantação do acolhimento, dificultando a sua institucionalização, pois, segundo Powell:

A institucionalização incompleta aparece associada, em geral, a intentos reformistas relativamente abrangentes que esbarram, quando de sua implementação, na resistência de interesses afetados pelas mudanças, de um lado, e na ausência de poder ou autoridade suficientemente sólida para conferir-lhes materialidade, de outro (Powel, 1991 apud CARneiro, 2000).

As gerências da SMSA/PBH são cargos de confiança do prefeito e do secretário de Saúde e, do ponto de vista político, altamente estratégicas. Por essa razão, é provável que as pessoas que ocupavam as gerências de Epidemiologia e Assistência, idealizadoras do conceito e gestoras da implantação da Proposta de Acolhimento em 1996, contassem com todo o apoio político do secretário e do prefeito para implantá-la. Tanto assim que a Proposta de Acolhimento veio a se tornar projeto de governo. É possível pensar que a dificuldade de institucionalizar a Proposta de Acolhimento estava localizada na resistência dos interesses que foram afetados pelas mudanças propostas e não na falta de apoio político.

O número limitado de consultas conferia aos trabalhadores das unidades a autonomia burocrática. Ou seja, respaldados pela regra não eram obrigados a atender pacientes além do estipulado. Acabar com a limitação de consultas, ao contrário, significava não ter nenhuma previsibilidade e controle sobre a entrada de pacientes. Tendo-se em conta as características da Proposta de Acolhimento, abrir a porta das unidades de saúde pode ter significado, para os trabalhadores das unidades de atenção primária do SUS em Belo Horizonte, perder a autonomia sobre a organização do próprio trabalho, criando as resistências que mudaram os rumos da Proposta de Acolhimento e se tornaram obstáculo à sua implantação.

Porém, a implantação de políticas públicas sempre envolve perdas ou ganhos, concentrados ou difusos, que atingem os atores envolvidos. Se as perdas ou ganhos convergem para um universo de atores cujo número é irrestrito, isso é menos significativo para o seu êxito. Porém, se as perdas ou ganhos convergem para um grupo delimitado e específico de atores, o êxito das políticas dependerá de estratégias de apoio e compensação das perdas.

O princípio do acesso universal e a Proposta de Acolhimento colocam os usuários do SUS no grupo de atores cujo número é irrestrito. O grupo obteve ganhos com a priorização do agudo, com a abolição das senhas e do comércio de lugares nas filas e com o fim das filas da madrugada. Entretanto, o que parece ter colocado em risco o êxito da Proposta de Acolhimento foi o fato de o grupo, específico e limitado, de trabalhadores das unidades de atenção primária ter qualificado como perda os custos e riscos pessoais inerentes à Proposta de Acolhimento.

A perda mais significativa sofrida pelo grupo de trabalhadores foi a extinção do número limitado de atendimentos diários, que lhes possibilitava a organização do próprio trabalho. Parece que eles vêm tentando resgatar essa autonomia 
burocrática por meio da "ritualização do acolhimento”. Horário, dia, local e equipe de acolhimento possibilitam a retomada da organização e planejamento da demanda que chega às unidades de atenção primária diariamente ${ }^{15}$.

Por tratar-se de política que implica mudanças de valores, atitudes e comportamentos, a Proposta de Acolhimento pressupõe custos, riscos e perdas pessoais para os trabalhadores, além de longo tempo para sua execução. Por essa razão, sua sustentabilidade depende do envolvimento continuado e da adesão dos trabalhadores desde o momento da definição do problema até sua avaliação, mesmo quando os resultados não são imediatamente visíveis. É muito importante que seja dada considerável atenção à questão da motivação durante a execução. Não foi suficiente, entretanto, que a Proposta de Acolhimento tivesse se tornado um projeto do governo, embora seja indiscutível que sua adoção foi e sempre será fundamental para sua sustentação.

Os trabalhadores das unidades de atenção primária do SUS em Belo Horizonte não participaram da definição do problema de acesso e da escolha da estratégia para sua solução; da decisão de abrir a porta e das agendas dessas unidades. Se os trabalhadores das unidades tivessem participado das decisões em todas as etapas, é muito provável que tivessem se mobilizado para evitar o retrocesso, pois envolvimento e adesão são obtidos em espaços híbridos de definição dos problemas, nos quais a tolerância ao dissenso é calculada coletivamente e a análise sobre a natureza do trade off implicado nas decisões é compartilhada.

Desde a definição do problema até sua implantação, a Proposta de Acolhimento esteve, predominantemente, associada à questão da organização e melhoria do processo de trabalho. Então, não é de se estranhar que ela continue sendo, predominantemente, utilizada como organizador do fluxo e planejamento do trabalho. Porém, a qualificação da relação trabalhador-usuário, com vinculação responsável e refinamento da escuta, também é mencionada como objetivo da Proposta de Acolhimento.

No entanto, ao implantar o Programa Saúde da Família (PSF) e utilizar territorialização e adscrição como estratégias de

"Na visão estratégica da implantação de políticas, a ideia de rota como trajetória preconcebida é substituída pela compreensão de que decisões autônomas induzem a um processo de aprendizagem, que tanto pode contribuir para reformular como pode, no seu limite, levar à reversão ou substituição da política."

organização e dimensionamento das áreas de abrangência, é que as unidades de atenção primária conseguem, simultaneamente, maior profundidade no conhecimento dos usuários - elemento essencial à qualificação da relação trabalhador-usuário, com vinculação responsável e refinamento da escuta, objetivos do acolhimento. "A complementaridade encontrada nas propostas do PSF e do acolhimento é fato 
a se destacar. A territorialização parece ajudar sobremaneira a um acolhimento formador de vínculos" (Silva; Pereira, 2003).

Assim, embora a Reforma Brasileira de Saúde inscrita na Constituição Federal de 1988 (CF/88) estabeleça entre suas diretrizes o universalismo, uma das concepções envolvidas com o PSF é a prática focalizada dentro do universalismo. As experiências de focalização têm comprovado que não há necessariamente conflito entre esses dois conceitos, universalidade e focalização, por isso mesmo não precisam ser excludentes (VIANA e DAL Poz, 1998).

\section{Conclusão}

O que mais se destacou na análise da formulação e implantação da Proposta de Acolhimento foi que suas dificuldades de institucionalização são decorrentes do fato de esses dois processos, mas principalmente a formulação, terem-se dado top-down, (de cima para baixo), do grupo gestor do nível central da SMSA/PBH para essas unidades.

$O$ acolhimento vem cuidando dos aspectos processuais da organização e planejamento do trabalho. A adscrição e territorialização, estratégias introduzidas com a implantação do Programa de Saúde da Família, cuidam da vinculação responsável, estabelecendo-se uma interdependência nos aspectos quantitativos e qualitativos, que complementam a proposta e deveriam ser melhor explorados pelos planejadores $\mathrm{da}$ política de saúde.

Mas os avanços observados relativamente à situação anterior ao PSF não devem motivar a ausência de uma avaliação rigorosa do impacto da Proposta de Acolhimento que, ao final, poderá resultar em nova proposição que se aproxime mais da execução.

(Artigo recebido em janeiro de 2007. Versão final em março de 2009.)

\section{Notas}

1 Coligação PCB, PC do B, PT, PV encabeçada pelo Partido dos Trabalhadores sob a liderança de Patrus Ananias, que assumiu a Prefeitura de Belo Horizonte no período de 1993 a 1996.

2 Centro de saúde é outra denominação para unidade de atenção primária.

3 Queiroz (1998).

4 Entrevista dos idealizadores da Proposta de Acolhimento à autora. Belo Horizonte (MG), novembro de 2005.

5 Entrevista dos idealizadores da Proposta de Acolhimento à autora. Belo Horizonte (MG), novembro de 2005.

6 Entrevista dos idealizadores da Proposta de Acolhimento à autora. Belo Horizonte (MG), novembro de 2005.

7 Número médio diário por equipe de saúde da família.

8 Entrevista dos trabalhadores à autora. Belo Horizonte (MG), maio de 2006.

9 Entrevista dos usuários à autora. Belo Horizonte (MG), maio de 2006.

${ }^{10}$ Conforme entrevista com os idealizadores da Proposta de Acolhimento (Brasília/Belo Horizonte, novembro de 2005), o problema era "garantir e ampliar o acesso que era limitado por um número predeterminado de consultas". 
11 Entrevista dos trabalhadores à autora. Belo Horizonte (MG), maio de 2006.

12 Conforme entrevista dos idealizadores da Proposta de Acolhimento à autora em Belo Horizonte (MG), em outubro de 2005, “[...] não se trabalhou muito aprofundadamente, pelo menos que eu me lembre, no levantamento de causas do problema”.

13 Conforme entrevista dos idealizadores da Proposta de Acolhimento à autora em Brasília/ Belo Horizonte, em novembro de 2005: "Na implantação tem uma coisa que é o ator dirigente. Que move isto, que puxa. [...] a implantação é essencialmente uma diretriz desse grupo dirigente[...]. É uma proposta da direção, e isso tem que ficar bem claro”.

14 Conforme entrevista com os idealizadores do acolhimento à autora em Belo Horizonte (MG), em outubro de 2005: “O problema era evidente. Na cabeça de quem dirigia, existia uma alternativa a ele, que já era a estratégia do acolhimento."

15 Conforme entrevista dos trabalhadores à autora em Belo Horizonte (MG), em maio de 2006: "Acolhimento não tem número e, quando você tem outras coisas para fazer, fica difícil. Temos que ter horário para acolhimento, senão não damos conta. O acolhimento é primordial para organização. Eu vejo acolhimento como planejamento."

\section{Referências bibliográficas}

Belo Horizonte. Secretaria Municipal de Saúde. Recomendacões para a Organização da Atenção Básica na Rede Municipal. Belo Horizonte: 2003. 25p.

BRasil. Ministério da Saúde. Cartilha da PNH: Acolbimento com classificação de risco. Brasília/ DF: Editora MS, 2004. 44p.

Carneiro, Ricardo. Estado, Mercado e o Desenvolvimento do Setor Elétrico Brasileiro. 2000. $400 \mathrm{f}$. Tese de Doutorado em Ciências Humanas - Universidade Federal de Minas Gerais, Faculdade de Filosofia e Ciências Humanas, Belo Horizonte.

O planejamento na esfera pública: fundamentos teóricos, possibilidades e limites operacionais. In: CarneIro, Carla Bronzo; Costa, Bruno Lazzarotti Diniz. Gestão Social: o que há de novo? Belo Horizonte: Fundação João Pinheiro, 2004. Vol. 2, cap. 3, p. 47-68.

Equipe de Saúde do Centro de Saúde Pedreira Prado Lopes. Estudo de demanda do acolhimento do Centro de Saúde Pedreira Prado Lopes. In: Seminário Atenção Básica SUS, Set. 2004, Belo Horizonte. Resumo dos trabalhos. Belo Horizonte: Prefeitura Municipal de Belo Horizonte, 2004. p.5.

GRINDLE, Merilee S. Restricciones políticas en la implementación de programas sociales: la experiencia latinoamericana. In: KLIKSBERG, Bernardo (Org.). Como enfrentar la pobreza? Aportes para la acción. Grupo Editor Latinoamericano, 1992. p. 109-125.

Guimarães, Eneida Maria Gomes Torres. Acolhimento no Centro de Saúde Noraldino de Lima: investigação sobre o acesso e resolutividade. 1997. Monografia de conclusão do Curso de Especialista de Enfermagem de Saúde Pública - Universidade Federal de Minas Gerais, Escola de Enfermagem, Belo Horizonte.

Lipsky, Michael. Los empleados de base en la elaboración de políticas públicas. In: Lecturas de Gestión Pública. 1ae ed. Madrid: INAP/Boletín Oficial del Estado, 1996. Cap. 13, p. 281-297. 
MALTA, Deborah Carvalho. Buscando novas modelagens em saúde: as contribuições do Projeto Vida e do acolhimento para a mudança do processo de trabalho na rede pública de Belo Horizonte, 1993-1996. 2001. 46f. Síntese da tese de Doutorado em Saúde Coletiva - Universidade Estadual de Campinas, Departamento de Medicina Preventiva e Social, Campinas.

Meny, Ives; Thoenig, Jean Claude. El marco conceptual. In: Las Políticas Públicas. Barcelona, Ariel, 1992. Cap. 3, p. 89-127.

Molina, Carlos Gerardo. Modelo de Formação de Políticas e Programas Sociais. In: Diseño y Gerencia de Políticas y Programas Sociales. INDES, 2002. p. 1-23.

QueIroz, Thaís de Melo. Implantação da estratégia do acolhimento no Centro de Saúde Serra Verde. 1998. 88f. Monografia de conclusão do IV Curso Superior de Administração Pública - Fundação João Pinheiro, Escola de Governo, Belo Horizonte.

Silva, Érika Marques Guimarães; PEREIRA, Rodrigo Pastor Alves. Acolhimento: das bases conceituais à organização do processo de trabalho das equipes de saúde da família do Centro de Saúde Vera Cruz. 2003. 16f. Monografia de conclusão do Curso de Especialização em Saúde da Família - Universidade Federal de Minas Gerais, Belo Horizonte. Silva, Pedro Luiz Barros; Melo, Marcus André Barreto de. O processo de implementação de políticas públicas no Brasil: características e determinantes da avaliação de programas e projetos. Núcleo de Estudos de Políticas Públicas/UNICAMP, Campinas, n.48, p. 2-16, 2000.

VianA, Ana Luiza D‘Ávila; DAL Poz, Mario Roberto. A Reforma do Sistema de Saúde no Brasil e o Programa de Saúde da Família. Physis: Revista de Saúde Coletiva. Rio de Janeiro, v. 8, n. 2, p.11-48, 1998.

Velloso, Bianca Guimarães; MAtos, Sonia Gesteira. A Complexa construção do SUS Belo Horizonte - os desafios que ele propôs. In: REIs, Afonso Teixeira dos et al. Sistema Único de Saúde em Belo Horizonte: reescrevendo o público. 1ํㅡ ed. São Paulo: Xamã, 1998. Parte II, cap.1, p. 83-102. 


\section{Resumo-Resumen-Abstract}

\section{A Proposta de Acolhimento: sua formulação e implantação nas unidades de atenção} primária do Sistema Único de Saúde no Município de Belo Horizonte Heloisa Helena Silva Moreira

A Proposta de Acolhimento teve por objetivo garantir o acesso às unidades de atenção primária do Sistema Único de Saúde (SUS) em Belo Horizonte, Minas Gerais. Este trabalho analisa e tenta compreender a notável distância entre a proposição e a execução da proposta nesse município. Usando contribuições teóricas do campo temático das políticas públicas na análise do contexto político-administrativo em que se desenvolveu a proposta, e utilizando as informações obtidas na pesquisa de campo com os principais idealizadores da proposta e alguns trabalhadores e usuários, foram identificadas, na sua formulação e implantação, informações que ajudam a entender a distância observada.

Palavras-chave: Proposta de Acolhimento, formulação, implantação, unidades de atenção primária.

\section{La Propuesta de Acogimiento: su formulación e implantación en las unidades de atención primaria del Sistema Único de Salud de la municipalidad de Belo Horizonte Heloisa Helena Silva Moreira}

La propuesta de Acogimiento tuvo como objetivo garantizar el acceso a las unidades de atención primária del SUS en la municipalidad de Belo Horizonte, Minas Gerais. Este trabajo analisa e intenta comprender la notable distancia entre la proposición y la ejecución de la propuesta en esta ciudad. Utilizándose de contribuciones teóricas del campo temático de las políticas públicas en el análise del contexto político-administrativo en el que se desarrolló la propuesta, y utilizando las informaciones obtenidas en la "pesquisa de campo" con los principales idealizadores de la propuesta y algunos trabajadores y usuarios, fueron identificadas, en su formulación e implantación, informaciones que ayudan a entender la distancia observada.

Palabras clave: propuesta de acogimiento, formulación, implantación, unidades de atención primaria.

The Welcome Proposal: its formulation and implementation in primary health care units of the Unified Health System - SUS in the region of Belo Horizonte city

\section{Heloisa Helena Silva Moreira}

The purpose of the welcome proposal was to guarantee access to the primary health care units of the Unique Health System - SUS in the city of Belo Horizonte, Minas Gerais. This work analyses and tries to understand the remarkable distance between the proposition and the implementation of the welcome proposal in this city. The theoretical contributions from the public policies scope and the data obtained through field research interviews with main proposal idealizers, workers and beneficiaries were applied to the analysis of the administrative and the political contexts of this proposal. It was possible to identify findings that helped understanding the distance observed between formulation and implementation.

Keywords: welcome proposal, formulation, implementation, primary health attention unit.

Heloisa Helena Silva Moreira é mestre em Administração Pública pela Fundação João Pinheiro. Analista de Políticas Públicas e psicóloga da Prefeitura Municipal de Belo Horizonte.

Contato: heloisahelenasm@yahoo.com.br 